\title{
Risk management method for small photovoltaic plants
}

\author{
Milena KIROVA \\ University of Ruse "Angel Kanchev", Ruse, Bulgaria \\ Preslava VELIKOVA \\ University of Ruse "Angel Kanchev", Ruse, Bulgaria \\ pvelikova@uni-ruse.bg
}

\begin{abstract}
Risk management is necessary for achieving the goals of the organization. There are many methods, approaches, and instruments in the literature concerning risk management. However, these are often highly specialized and transferring them to a different field can prove difficult. Therefore, managers often face situations where they have no tools to use for risk management. This is the case with small photovoltaic plants (according to a definition by the Bulgarian State Energy and Water Regulatory Commission small applies to systems with a total installed power of $200 \mathrm{kWp}$ ). There are some good practices in the energy field for minimizing risks, but they offer only partial risk prevention and are not sufficient. Therefore a new risk management method needs to be introduced. Small photovoltaic plants offer plenty of advantages in comparison to the other renewable energy sources which makes risk management in their case more important. There is no classification of risks for the exploitation of small photovoltaic systems in the available literature as well as to what degree the damages from those risks could spread. This makes risk analysis and evaluation necessary for obtaining information which could aid taking decisions for improving risk management. The owner of the invested capital takes a decision regarding the degree of acceptable risk for his organization and it must be protected depending on the goals set. Investors in small photovoltaic systems need to decide to what degree the existing risks can influence the goals previously set, the payback of the investment, and what is the acceptable level of damages for the investor. The purpose of this work is to present a risk management method, which currently does not exist in the Bulgaria, so that the risks and the damages that could occur during the exploitation of small photovoltaic plants could be identified and the investment in such technology-justified.
\end{abstract}

Keywords: risk management, method, small photovoltaic plants, Monte Carlo simulation, expert evaluations.

Please cite the article as follows: Kirova, M. and Velikova, P. (2016), "Risk management method for small photovoltaic plants", Management \& Marketing. Challenges for the Knowledge Society, Vol. 11, No. 3, pp. 498-512. DOI: 10.1515/mmcks-2016-0012

\section{Introduction}

Risk management is necessary for every organization. In order for every business to achieve its goals, the risks that could influence them are to be managed well. For that purpose approaches, methods, instruments, technologies, etc. that could make this task possible are needed. However, most risk management instruments are created 
specifically for a particular field and transferring them to another one is often almost impossible. When considering the energy field in particular, it can be concluded that there are some good practiced to reduce risk. Therefore, managers, investors, business owners, etc. are often facing situations in which such instruments are needed but are not available.

Photovoltaic installations (PVI) have plenty of advantages to other energy sources, discussed in detail in (Velikova, 2012). PVI, as a type of renewable energy source (RES), help environmental preservation, they can be built close to the consumers so that transition losses are minimized, and on various locations like roofs, walls and on the ground, the investment and their exploitation costs have decreased rapidly in the past few years and this type of technology has become more and more available for construction. Small photovoltaic plants, according to a definition by the Bulgarian State Energy and Water Regulatory Commission (SEWRC, Decision № C-28 from 29th Aug 2012, p. 2) are systems with a total installed power of $200 \mathrm{kWp}$ which have more advantages in comparison to larger PVI. Small PVI usually do not have the support of a mother-company which makes them more vulnerable compared to other businesses. Also, they cannot influence the local environment negatively. Small photovoltaic systems are cheaper to invest in, they also require a smaller area, their construction is faster and there are many such plants existing in Bulgaria, compared to larger systems. That is why creating a risk management method for small PVI has priority compared to other sizes and types of RES. The first steps of this method were presented in Velikova and Kirova (2014).

There is no system which presents the risks to which the exploitation of small PVI is exposed and there is no information regarding how much would the damages from the potential risks cost. Investors in PVI need to have this information in order to decide what level of risk is acceptable for them depending on the goals they have set for their investment's management. Several categorizations of these risks exist (Cortez et al., 2012), but they devide the risks only into external and internal. Also, the most popular methods and approaches for risk evaluation were classified and the most appropriate one was selected - Monte Carlo simulation. An example for the use of this method for risk management of an exemplary system can be found in Kirova and Velikova (2014). The correlation between the yearly change in the preferential purchase price for enegy produced by PVI as a main stimulus for investing more in this technology, and the change in the quantity of installed power were analysed in Kirova and Velikova (2013). According to Lüthi and Wüstenhagen (2012), two factors are most significant - the length of the administrative process and the level of preferential price. Sarasa-Maestro et al. (2013) point out that preferential tariffs are often used to stimulate the development of PVI and are the most effective profit system for increasing the development of the various technologies for generating electricity.

A method for risk management of small PVI is needed for their owners and managers. Such a method should be able to point out which risks could occur and to what extent while the systems are in exploitation so that the payback of the investment could be justified. The purpose of this report is to present a method for managing the risks of small PVI during their installation. The dynamic processes in the legislation in this area increase the time of construction and lead to extra, unexpected financial expenses and problems to which the systems are exposed. This leaves the Vol. 11, No. 3, Autumn, pp. 498-512, ISSN 1842-0206 | Management \& Marketing. Challenges for the Knowledge Society 
investors in the technology in situations where they have to search for decisions through which the payback of the investment is to be guaranteed. As a result, the risk management during the exploitation of small PVI would lead to improving the decisions taken and the systems' management which will give an opportunity to sustain the investors' interest.

\section{Literature review}

The need for environmental preservation, ensuring availability of energy sources, the growing dependance between environment and development make risk management in the environmental sector an economic and social priority. Guaranteeing economic sustainability requires an integrated approach regarding potential risks (Olaru et al., 2014). Risk management becomes more and more important when modelling prognoses (Shorter and Rabitz, 1997). On the overall, many organizations ignore risks which could lead to losses, if those risks occur (Boycheva, 2007). Risk management costs time and money, but without it the possibility for a failure increases considerably (Branscomb and Auerswald, 2001). Photovoltaic installations (PVI) have plenty of advantages. Their functioning is not related to petrol prices and they have almost no exploitation expenses because almost all expenses come under the form of a preliminary investment. Furthermore, this technology decreases or eliminates a number of risks like creating expensive extra power (Awerbuch, 2000). Their simple design and the need for almost no maintenance makes this technology more and more demanded (Parida et al., 2011). Investing in PVI is considered needed and necessary for the environment (Fthenakis and Moskowitz, 2000). Ninetyeight percent (98\%) of the green energy produced in Southeast Bulgaria (EVN Bulgaria, 2012) is generated by PVI which means that those systems are widely spred.

There are plenty of methods and approaches for risk evaluation 84 out of which are defined as essential (Vladimirov, 2009). Some methods are used more widely like the Monte Carlo (MC) simulation method among others (Mitev, 2007). MC is considered to be the most popular method for risk evaluation (Arunraj et al., 2013). MC simulations are extremely flexible and can be used to study very complex problems like evaluation of the reliability of photovoltaic-wind hybrid system (Zhang et al., 2013). The wide use of powerful computers and the development of easy-to-use electronic tables make the instruments from the management sector much more accessible for a considerably larger audience (Ragsdale, 2012).

A good way to conduct a Monte Carlo simulation is to use the functionalities of Microsoft (MS) Excel. If we want to calculate precisely the probability of occurance of an uncertain event (Microsoft, 2014) the Monte Carlo simulation offers a solution: the method can present an accurate picture of what could happen and of how likely is for an event to happen. There are many tools (software) for simulation for different applications but even still Microsoft Excel is a very good instrument (Guerrero, 2010). It can be applied easily and effectively when illustrating simulational modelling (Evans and Olson, 2001; Mun, 2006) and that it why it is used (Wang et al., 2011). Many of the different softwares (Goldsim (Goldsim, 2014), Analytica (Lumina Decision Systems, 2014), SimulAr (Machain, 2010), Minitab Statistical Software (Sheehy and Martz, 2012), etc.) are available only through a purchase while MS Excel is an implicit business requirement. Another one of the advantages of Excel is that it can present a 
graph right away and it is compatible with text processors, data bases, etc. (Wang and Huang, 2012).

The information used in $\mathrm{MC}$ - the range of minimum and maximum losses by each probable risk is obtained through expert evaluations. The values of a certain event and the probability for its occurance can vary widely (Georgiev, 2002). The expert evaluation can make those variations more precise so that the data which is generated is close to reality for the conducted research. When there is a problem related to a decision that needs to be taken among many alternatives, none out of which seems appropriate, and when a decision cannot be based on reliable mathematical models or statistical dependancies, "the only remaining option to solve the problem could be using an expert evaluation" (Mehandjiev, 1996, p. 165). It is estimated that when the method for expert evaluation is correctly chosen the error of the result is between $5 \%$ and $10 \%$ and is comparable to the error of the standard instrumental methods (Malakov, 2008). Also, the expert evaluation is cheap because it uses simple paper interview cards.

There are two ways to conduct an expert evaluation - through an interview and through the Delfi method. Delfi would take considerably much more time and it will make the results given by the experts who have taken part in the research similar. This approach will also influence the results and that is why interviews are made. During the interview the experts will not have access to information given by other participants and therefore the results given will be more objective. According to specialists on expert evaluations (Minev et al., 2014) the optimum number for interviewed experts is 15 .

Many organizations use a subjective classification which defines the probability for risk occurance as belonging to one of three categories - low, average and high. This does not allow for actual risk management because there is no specific data in numbers, and also because these terms could be defined differently by the various managers (Hubbard, 2007).

\section{Research methodology}

The object of the research is chosen after analysis of the different types of RES - small PVI with total installed power of up to $200 \mathrm{kWp}$.

There is lack of information regarding the damages that could occur from potential risks described in previous researches. That is why in order to obtain this information a method needs to be chosen - expert evaluations are used. While the interviews are conducted, an enquiry card is prepared in advance. It consists of two parts - an introduction, stating who is making the research, why, what information is needed and how it will be used. The second part contains the questions. The information obtained from them will be used in the Monte Carlo simulation in order to establish the degrees of influence of the damages from the various risks. The information from the expert evaluations on small PVI is used to make simulations for systems with 5 to 30,50 to 100,100 to 150 and 150 to $200 \mathrm{kWp}$. Such a devision allows us to present a distribution of the data. The first simulation is a bit different this is because the smallest systems for which we have available data has a total power of 4,8 kWp and there is no data for systems with power between 30 and 50 $\mathrm{kWp}$. Also, the preferential price for those systems is different for PVI with power up
MMCKS

501 
to 5 , between 5 and 30, and between 30 and $200 \mathrm{kWp}$. This risk management method is also approbated through a simulation with data for a specific system with 25.92 $\mathrm{kWp}$ power - its owner participated in the research by providing information. The first stages of the risk management are examined - identification and evaluation of risks. But even still, the method provides the means through which a managerial decision can be taken.

\section{Preparation and implementation of expert evaluations for small PVI}

The preparation and implementation of expert evaluations includes the following steps in chronological order:

(1) Risks description. For the purpose of implementing an expert evaluation it is necessary to first point out the risks for which specific information is needed. The level of acceptability of risks is defined by a compromise level of risk - a certain balance between expected gain and threat of loss (Marinova, 2012). The categorization of the risks, prepared in advance, allows the information to be used to extrapolate the main risks for small PVI so that the expert evaluation can retrieve various data regarding the diversity of risks which could occur based on the realization of one or more of the probable risks. Such categorization is presented for the first time by the same authors in (Kirova et al., 2012).

(2) Preparation of the questions for interview. After analysis of certain risk categories and extracting the main ones from the list, the questions for interview should be formed. In this case the information needed refers to minimum and maximum damages that could occur, in BGN, if a certain risk arises. This is how all experts should provide information so that it could be processed afterwards.

(3) Profiling which experts should be interviewed (specialists, consultants, project managers, etc). The experts' profile is formed on the database of the information existing in the accessible scientific publications and books.

(4) Organization and implementation of the interviews.

(5) Processing and analysis of the results obtained.

\section{Method of the research}

There is a large variety of methods and approaches for risk management which makes it almost impossible for all of them to be collected, reviewed and presented in detail. A reliable choice for a method could be taken based on which ones are more popular and which one of them would suit the purpose of the research.

The success of the experiment largely depends on its overall organization and implementation. It would be pointless to process data mathematically if the initial information is wrong, partial or inaccurate. That is why in order for the experiment to be well organized and implemented a plan needs to be developed to place in logical order all the questions to be solved related to the execution of the experiment. The order of the questions to be solved in practice depends on the specific object.

In this case the structure of the work is as follows:

(1) Defining the object and subject of the research. The object of the research is represented small PVI and subject of the research are the risks these systems are exposed to. 
(2) Purpose of the research. The purpose of the research is to evaluate the damages from the probable risks, to which the exploitation of small PVI is exposed, in order to improve their management and the degree to which they influence the payback of the investments in such technology. In order to implement the purpose of the research, the following tasks need to be performed: to collect data from experts in the PVI field regarding precise damage costs for risks, related to the exploitation of small PVI; to analyze the data obtained using the method Monte Carlo simulation; to establish what damages could occur if those risks take place and what is the percentage probability for that to happen.

(3) Defining parameters of the research. The probable damages need to be defined in a range with a minimum and maximum financial value which would allow their analysis afterwards.

(4) Conditions and limits of the research. The research needs to be clear, precise, understandable and generally accessible so that it can be easily understood and applied by those interested. The data from the experts needs to be full, precise and authentic.

Regarding the object of the research, the risk management of small PVI during their exploitation on the territory of the country is reviewed. This type of RES has a number of advantages over the other ones. The PVI are widely spread in Bulgaria which makes their risk management a priority to the other RES. The territorial, urban and rural development act does not make a difference between systems, placed on the roofs of houses or industrial buildings, or small PVI in the field, or façade or other types of constructions, with built-in photovoltaic elements in the front of the building. An expert evaluation for a particular type of PVI would take a large amount of time, considering the fast development of the technology, the constant decrease of their price and the preferential purchase price. That is why there is a possibility to reach to a difference between the correctness of the data at the beginning and at the end of the research which would distort the results to a degree beyond the assumptions made. Consequently, the current research will collect data for risks for small PVI without regard of their location.

Regarding the subject of the research, the exploitation of this technology is subject to many risks which put the focus on the work and excludes from the purpose of the research risk management during the installation of the systems. According to the decision № C-19 from 28th Jun 2013 of SEWRC, the admissible exploitation expenses that are subject to regulatory control, are related to the exploitation and maintenance of the installations according to the corresponding technical standards. These are mainly costs for environmental preservation, salaries, materials, repairs and upkeep, insurances, administrative expenses, related to the management of the organization, expenses for communication and monitoring, according to Energy from renewable sources act and other expenses, related to the exploitation process. The application of the method developed for risk management of small PVI during their exploitation uses damages from probable risks, production, deductions for capital investments and planned profit - all for one year, considering the average effective working hours of the system on the territory of the country, damages from probable risks according to the expert evaluations, and price for the investment and preferential purchase price according to SEWRC at the moment of implementation of the research.

Vol. 11, No. 3, Autumn, pp. 498-512, ISSN 1842-0206 | Management \& Marketing. Challenges for the Knowledge Society 
(5) Criteria for object evaluation. A criterion for object evaluation is the financial value of the construction of a small PVI, including maintenance costs. It is necessary to establish to what extra expenses the probable risks could incur and in what percentage of the cases the investment in a small PVI will be justified, i.e. the expenses will not be larger than the incomes.

(6) Algorithm for evaluation. The method for risk evaluation is based on value indicators. It is necessary to establish an evaluation scale to be used by each expert. In this particular case, due to lack of data for comparison, the experts will be given the freedom to provide ranges which will afterwards be grouped according to their own values. The laws and regulations which state the requirements for PVI construction, point out risks which could occur when building the system and in relation to its maintenance. The question list for the research will include such questions which could also give extra information like frequency and stage of risk occurance as well as probability for it to take place, in percentage, besides the compulsory questions regarding damages from the potential risks.

(7) Organization of the research. The order of the research is as follows: to choose well qualified experts to provide the needed information; to obtain their consent to participate in the team of experts for the research; to present before them the purpose of the research, the way the the results will be used and the evaluation procedure; to hand out the enquiry cards prepared in advance for the interviews.

(8) Continuation for the research.The period set for the research is as follows: Oct 2014 - Jan 2015.

(9) Number of the participating experts. It is considered that 15 experts is the optimum number. If only a few people participate, there will not be sufficient statistical reliability and sustainability of the evaluation. This number can be smaller (which will be efficient from organizational and economic points of view) without those possible negative effects if better experts are chosen. According to others, the best number is between 7 and 20 (Hristova, 2007) while others claim that the experts should be at least 5 (Vasilev et al., 2013).

(10) Method for processing of the information. Before the results are processed they need to be in a form ready to conduct the analysis. The damages from the probable risks will be calculated per $1 \mathrm{kWp}$ installed power which will allow for the data to be processed. The expert evaluations will be made with specialists on small PVI, therefore the information has to be for systems with different installed power within this limit. In this way the results will be various and more complete. The information provided will be used for simulations for systems with 5 to 30,50 to 100 , 100 to 150 and 150 to $200 \mathrm{kWp}$ power. The results will be analysed so that a pattern for small PVI is formed and also with the purpose to find out what differences there are for risk damages for systems with different power capacities.

(11) Results interpretation.The analysis of the results aims at finding out what damages could occur for small PVI and what is the percentage for that. The use of MS Excel provides for the opportunity to present a histogram which can illustrate the results.

(12) Conclustions from the research. 


\section{Choice of research approach}

The expert evaluation is based on the use of the experts' abilities (their knowledge, skills, experience, intuition, etc.) to give an evaluation which is closest to reality. The chosen approach has a number of advantages to the other approaches. During the expert evauation a number of specialists in a certain field deliver their opinion on a problem that usually does not have a basis for comparison, like the problem in this research. Their opinions are taken into consideration and a decision is taken based on the prevailing opinion. Those experts often have considerable but not officially presented information. The purpose for using it is to create a unique and replicable procedure for taking an objective decision, based on experience and knowledge in a certain field, in this case PVI, given by well selected experts who correspond to certainly estsablished conditions.

A main advantage of this method is its proven objectivity. The method also gives an opportunity for a personal contact with the specialists. This approach allows them to ask clarification questions which will decrease the risk the questions to be understood incorrectly and guarantees presentation of more accurate answers (an opportunity that the other popular methods like filling out questionnairs does not provide. Another advantage of the method is that the answers of the experts are anonymous. The independent work of the specialists guarantees lack of emotional influence with the answers of their colleagues. This method allows for obtaining information relating to the future which means that it can be used for making prognoses. The participation of highly knowledgeable specialists with experience provides for a high level of accuracy of the prognoses. The expert evaluations allow for a fast and easy extraction of best of the knowledge and skills by some of the most qualified experts. The information collected in this way represents the objective side of the event that is in the researcher's interest (except for when incorrect information is provided on purpose). On one side, the opinions of people are collected, but on the other - these opinions contain summarized and concentrated knowledge, intuition and experience of many specialists. The $90 \%$ confidence interval is used when processing the data from the interviews with the simulations.

Some disadvantages of the expert methods include that the interviews may continue longer than the initially planned period, for example if the necessary number of experts cannot be insured for participation precisely for that time length.

The ways and goals of the research need to comply with the object of interest. The researcher develops an enquiry card, organizes and conducts the interviews. Number ranges will be used for the damages from risks. The experts will be asked to give their opinions on the problem of interest. Each expert will be chosen anonymously and will be reached in written. With e-mails or on the phone the expert will be informed that his opinion is needed for a research and his consent for participation will be asked for. During the interview every expert will get a list with a description of the risks, and will be asked to appoint ranages in BGN for the damages from the probable risks, as well as the expected frequency and percent probability for the occurance of events which could lead to losses. In order to obtain results that are objective as much as possible, the data that is available to the interviewer will not be provided to them and they will not interact between each other, i.e. the evaluations will be carried out in isolation of the participants who will take part. The interviewer 
is to stay neutral when asking questions and should not direct the questions towards a specific answer.

There are two ways to organize an expert evaluation - through an interview and through the Delfi method. The second one is not appropriate in this case because it takes considerably more time. Also, when it is used, the work takes place in a few stages, and every next stage the questions can change in order to provide more precision and depth of the research. After all results are available, the average one for the group is calculated and each expert gets somebody else's provided opinion in writing. In this way every participant can review his opinion and decide whether to find more arguments for it or whether it can be changed. Then, each expert presents anewly his opinion. This procedure repeats a few times, usually 2 or 3, until all answers become the same. In both cases the enquiry cards would be the same so the quality of information will not be limited if interviews are preferred. Their use has the advantage that the experts will not be influenced by each other when giving answers. The purpose of using this method is not to get equal and/ or average responses which is what Delfi does and that is why it will not be used.

Monte Carlo uses the influence of each range of damages appointed by the experts and their impact on the final result is proportional. That is why the concordation of opinions method is not used either - because it is not necessary. In this case the purpose is to see what the ranges of damages that could occur from probable risks are. Using Delfi would distort the data because those damages could vary in a different degree which is one of the factors because of which it is expected that there will be a slight difference between the data received from the participants. Such a difference could also occur because the experts have knowledge for different systems - connection to the grid, power, producer, location, angle, climate conditions, etc. which could influence the results, even though insignificantly. That it is why it is expected that some ranges of damages could have a 0 for a minimum value (for example, damages in the grid could not occur for systems that are not connected to it). The interview method is considered successful when the expert is interviewed without initial preparation. The experts chosen should be well informed and should be aware of the purpose of the research and the way the information from them will be used. This preliminary information is necessary in order to ensure that the opinions given are as close to reality as possible and will correspond to the purpose of the research.

\section{Profiling the experts}

Considering the questions that are to be asked, the experts participating should know the way a PVI is constructed and/ or how it functions and they should also work in this field when asked to participate in the research which would provide a higher guarantee for accuracy of the results. The photovoltaics represent a dynamicly changing technology - their value and exploitation expenses decrease constantly, their efficiency increases, new systems are being invented, etc. That is why experts who are not active in this field could provide data which could be partially incorrect or outdated. The specialists need to be able to give accurate and up-to-date information because the sector develops rapidly and the risks also change along with the developments. Either way, most of the power installed existing in the country has 
strated functioning only a few years ago. That is why it is almost impossible to receive outdated information, especially from PVI owners.

In order to ensure objective selection of the specialists who will take part in the research the people selected need to have different experience. That is why they are divided into 4 categories:

(1) Producers of PVI, their components and parts.

(2) A physical person or legal entity - investors in PVI. These could be organizations that perform activities including production, distribution, transport, accumulation, distribution and/ or trade with electricity, as well as participation in such organizations, as well as organizations that perform their activity under code D (production and distribution of electrical and thermal energy and gas substances) according to the Classification of economic activities in Bulgaria (NSI, 2008). The codes are available online and which one refers to a particular company could be easily checked in the Commercial register at the Registry Agency of the Ministry of Justice by name and Bulstat of the organization and all this information is publicly accessible.

(3) Persons who consult PVI construction, including project experts who work for a private or non-governmental organization or own such a company.

(4) Scientific workers who conduct research in the PVI field (engineers, lecturers, researchers). Those experts need to work on the territory of the country so that they could present relevant data for the research and so that they have the necessary education, experience, knowledge and abilities that the people in the mentioned categories must have. This would guarantee their competence in their work and would provide data that is closest to reality. At the same time the literature provides some tendencies when compiling the experts' profile. They have to be competent professionals, with a high level of knowledge, intuition and ability to think in perspective, sensible and with the ability to make analogies (Hristova, 2007), honest, with experience in this field not less than 4 years. They have to possess maximum theoretical knowledge in this area and as much experience as possible. Directions in this field could be given by the position of the person in the company, and the degree and rank that he has. After a research regarding who is appropriate for being interviewed, a list with their names is prepared and the interviews are organized. This is one of the most difficult and responsible tasks to be performed as part of conducting the expert evaluations and much of the results depend on it. After choosing experts and obtaining their consent for contribution, a program for their interviews is made. Each expert is to be interviewed alone and without any communication with other participants. If the criteria for choosing experts are complied with and the data provided by them is accurate the results should be close.

\section{Compiling interview questions}

The information searched for will be for small PVI. It has to respond to the requirements of the method which will be used to predict the future behavior of the system. The data has to be understandable so the method could be applied and respond to the restrictions set.

The questions in the interview will be:

(1) Frequency (minimum/ maximum) and stage of origin

(2) Percentage probability for the risk to occur (minimum/ maximum)

Vol. 11, No. 3, Autumn, pp. 498-512, ISSN 1842-0206 | Management \& Marketing. Challenges for the Knowledge Society 
(3) Expected damages (minimum/ maximum value in BGN)

(4) Is risk management necessary (yes/ no)

(5) Taking a decision to invest if the risk occurs (give a value between 5 (yes) and 1 (no), according to table 1)

(6) Other notes and comments

The risks included in the research are the following:

(1) Unfavourable and unstable climate

(2) Risks of injury for the staff during the construction and maintenance of the systems

(3) Faults with the system's construction

(4) Faults with the system's maintenance

(5) The need to often reset the system

(6) Opposition during any of the stages of the system construction (obtaining a permission, construction, exploitation, etc.)

(7) Production interruption

(8) Limiting the production

(9) Violation. Vandalism

(10) Damages of the system's components

(11) Damages in the grid, receiving the energy produced

(12) Unfavorable changes in the legislation and administrative acts

(13) Unfavorable changes in the subsidizing

(14) Unfavorable changes in the system costs

(15) Risks of change of the requirements, related to the systems' liquidation, the work with dangerous waste and their recycling

(16) Influence of the corruption changes

(17) Other possible risks as a result of (local, geopolitical, economic, etc.)

In this case the questions relate to the development of the risks in time since the experts will be expected to comment on the stages of risk development construction and functioning of the system, decrease in the efficiency of the system, recycling period of the technology. The analysis of the risks is made based on literature review but in this case the expert data could have a role in precising those risks. Asking more questions allows for getting more information.

\section{Organization and conducting the research}

There are various ways to obtain the information needed to conduct the research. In this case the experts will be selected using a documental approach randomly. Each one, corresponding to one of the categories in the research and the rest of the conditions stated in advance, will be given the opportunity to participate in the interview.

\section{Processing and analysis of results}

The expert evaluation will assist taking a decision related to the choice to invest in a small PVI, based on collected and analyzed data in ways, explained in the method.

After the end of the interviews, the information has to be processed so that the data is summarized in ranges of values, including minimum and maximum accepted values, i.e. the information obtained will be processed in a way that allows its use with Vol. 11, No. 3, Autumn, pp. 498-512,ISSN 1842-0206 | Management \& Marketing. Challenges for the Knowledge Society 
the Monte Carlo method. The analysis will be made with MS Excel because it is widely used and well-known. On the question about taking a decision to invest when a risk occurs, each expert has to give a value (a number) to every risk according to every criterion (indicator). Usually a table with a scale for evaluation is created or different scales are created for the different criteria or indicators (groups of indicators). The scales for evaluation are usually from 1 to 10 but scales from 1 to 3 , from 1 to 6 , from 2 to 6 , etc. are also used. A scale with value of the assessment from 1 to 5 will be used (table 1):

\begin{tabular}{|c|c|c|}
\hline $\begin{array}{l}\text { Value of the } \\
\text { assessment }\end{array}$ & Common description & Definition \\
\hline 5 & $\begin{array}{l}\text { Exceptionally excellent } \\
\text { value }\end{array}$ & Most qualities of the option are above the desired values. \\
\hline 4 & Value above the average & Some qualities are above the desired values. \\
\hline 3 & Average value & Few weaknesses; generally the desired values are achieved. \\
\hline 2 & Value below the average & $\begin{array}{l}\text { Existence of defects. Some qualities are below the desired } \\
\text { values. }\end{array}$ \\
\hline 1 & Unacceptable option & Most qualities are below the desired values. \\
\hline
\end{tabular}

\section{Conclusion}

There are some good examples for partial risk prevention in the energetics field which means that other approaches need to be searched for. An algorithm, based on which expert evaluations are prepared and implemented is presented. A profile of the specialists to participate in the research is created. The method of the research is presented and justified. It can be used to obtain data related to damages from probable risks to which small PVI' are exposed. Through this method the information provided is in the form and type that is appropriate to process for delivering data regarding what are the possibile damages to risks related to the exploitation of small PVI and what is the precise percentage of probability for damages of certain ranges to occur. Currently this method was used and the research is finished. The information obtained from it was used for risk management for the exploitation of small PVI and the results are presented in the dissertation this material is part of. The method described in this article is implemented and approbated by using the data provided in the means described in the text, and is related to the specifics of the photovoltaic market and energy field in Bulgaria.

\section{Disclaimer}

A shorter version of this article was presented during the 10th International Conference on Business Excellence in Energy, Climate Change and Sustainability (ICBE) in Bucharest, Romania, on the 3rd of March 2016, and published in the conference proceedings.

\section{References}

Velikova, P. (2012), "Tendencies in the development of the photovoltaic market in Bulgaria", Proceedings of Ruse University, Vol. 51, No. 1-2, pp. 119-124. 
SEWRC. (2012), "Decision № C-28 from 29th Aug 2012 of SEWRC, available at: http://www.dker.bg/files/DOWNLOAD/res-C28-29082012.pdf, (accessed Jun 21, 2013).

Velikova, P. and Kirova, M. (2014), "Expert evaluation for risk management of the exploitation of photovoltaic installations”, Annals of „Eftimie Murgu” University Reşiţa, Fascicle II. Economic Studies, No XXI, pp. 383-391.

Cortez, L., Cortez, J.I., Aguilar, G.M., Rueda, S.M., Rodriguez, A.D., García, G.T., Camacho, A.P. and Hernandez, EH. (2012), "Determination of the Efficiency of a Photovoltaic System Operating On the Climatic Features of Mexico", International journal of advanced renewable energy research, Vol. 1, No. 11, pp. 611-617.

Kirova, M. and Velikova, P. (2014), "Monte Carlo simulation for risk assessment of photovoltaic installations", CTIC - Proceedings in Conference of Informatics and Management Sciences, University of Zilina, Slovak Republic, pp. 82-87.

Kirova, M. and Velikova, P. (2013). "The Preferential Purchase Price of Electrical Energy from Photovoltaics in Bulgaria - Political Risk at Their Construction", Journal of Entrepreneurship \& Innovation, Vol. 5, pp. 110-127.

Lüthi, S. and Wüstenhagen, R. (2012). "The price of policy risk - Empirical insights from choice experiments with European, photovoltaic project developers", Energy Economics, Vol. 34, No. 4, pp. 1001-1011.

Sarasa-Maestro, C.J., Dufo-López, R. and Bernal-Agustín, J.L. (2013), "Photovoltaic remuneration policies in the European Union", Energy Policy, Vol. 55, pp. 317328.

Olaru, M., Şandru, M. and Pirnea, I.C. (2014), "Monte Carlo method application for environmental risks impact assessment in investment projects", Procedia Social and Behavioral Sciences, Vol. 109, pp. 940-943.

Shorter, J. and Rabitz, H. (1997), "Risk analysis by the guided monte carlo technique", Journal of Statistical Computation and Simulation, Vol. 57, No. 1-4, pp. 321-336.

Boycheva, E.S. (2007), "The risk in the enterprise and its management", Controlling, Vol. 1, pp. 15-17.

Branscomb, L.M. and Auerswald, P.E. (2001), Taking technical risks, Cambridge: The MIT Press.

Awerbuch, S. (2000), "Investing in Renewables: Risk Accounting and the Value of New Technology", available at: www.awerbuch.com/shimonpages/shimondocs/solar-roofs-policy.pdf, (accessed March 4, 2014).

Parida, B., Iniyan, S. and Goic, R. (2011), "A review of solar photovoltaic technologies", Renewable and Sustainable Energy Reviews, Vol. 15, pp. 1625-1636.

Fthenakis, V. and Moskowitz, P. (2000), "Photovoltaics: Environmental, Health and Safety Issues and Perspectives", Progress in photovoltaics: research and applications, Vol. 8, Issue 1, New York: John Wiley \& Sons, pp. 27-38.

EVN (2012), "Information from EVN Bulgaria", available at: https://www.evn.bg/Medii/VEI13_08.aspx?listnode=/Medii, (accessed August 19, 2012).

Vladimirov, L. (2009), "A comparative analysis of the methods for risk assessment of potentially dangerous objects and activities, Proceedings of Ruse university, Vol. 48, No. 1.2, pp. 132-136.

Vol. 11, No. 3, Autumn, pp. 498-512, ISSN 1842-0206 | Management \& Marketing. Challenges for the Knowledge Society 
Mitev, V. (2007), "Evaluation of the reserves and resources of the deposits of polymetallic ores", Annals of the University of mining and geology "St. Ivan Rilski", Vol. 50, No. IV, pp. 53-58.

Arunraj, N.S., Mandal, S. and Maiti, J. (2013), "Modeling uncertainty in risk assessment: An integrated approach with fuzzy set theory and Monte Carlo simulation", Accident Analysis and Prevention, Vol. 55, pp. 242-255.

Zhang, P., Li, W., Li, S., Wang, Y. and Xiao, W, (2013). "Reliability assessment of photovoltaic power systems: Review of current status and future perspectives", Applied Energy, Vol. 104, pp. 822-833.

Ragsdale, C.T. (2012), Spreadsheet modeling \& decision analysis, Mason, USA: SouthWestern. Cengage Learning.

Microsoft. (2014), "Introduction to Monte Carlo simulation", available at: http://office.microsoft.com/en-us/excel-help/introduction-to-monte-carlosimulation-HA001111893.aspx, (accessed February 13, 2014).

Guerrero, H. (2010), Excel Data Analysis, Berlin: Springer.

Evans, J. and Olson, D. (2001), Introduction to simulation and risk analysis, Upper Saddle River: Prentice-Hall Inc.

Mun, J. (2006), Modeling risk: applying Monte Carlo simulation, real options analysis, forecasting, and optimization techniques, Hoboken: John Wiley \& Sons.

Wang, Y., Cao, Z. and Aua, S. (2011), "Practical reliability analysis of slope stability by advanced Monte Carlo simulations in a spreadsheet", Canadian Geotechnological Journal, Vol. 48, No1 1, pp. 162-172.

GoldSim (2014), "Monte Carlo Simulation Software for Decision and Risk Analysis", available at: http://www.goldsim.com/Home/\#>, (accessed March 18, 2014).

Lumina Decision Systems (2014), “Analytica Editions". Available at: http://www.lumina.com/products/analytica-editions/, (accessed March 18, 2014).

Machain, L. (2010), "Montecarlo Simulation in Excel", available at: http://www.simularsoft.com.ar/SimulAr1e.htm, (accessed March 18, 2014).

Sheehy, P. and Martz, E. (2012), "Doing Monte Carlo Simulation in Minitab Statistical Software", available at: http://www.minitab.com/en-us/PublishedArticles/Doing-Monte-Carlo-Simulation-in-Minitab-Statistical-Software/, (accessed March 18, 2014).

Wang, J. and Huang, D. (2012), "RosenPoint: A Microsoft Excel-based program for the Rosenblueth point estimate method and an application in slope stability analysis", Computers \& Geosciences, Vol. 48, pp. 239-243.

Georgiev, R. (2002), Risk management in entreprenural activity, Sofia: "Financial House Logos-TM" JSC and the Institute for interdisciplinary research.

Mehandjiev, M. (1996), Decreasing and minimizing waste the mining, mineral processing and metallurgical enterprises, Sofia: Coopconsult.

Malakov, I. (2008), "Classification of methods for determining the technical and economic performance of systems for low-cost automation", Scientific reports of the Scientific Technical Union in mechanical engineering, Vol. 3, No. 106, pp. $52-62$.

Minev, B., Naydenov, N. and Nedyalkov, A. (2014), "Methodology for research of technical equipment at machine-building enterprises", Proceedings of 

145-155.

Hubbard, D.W. (2007), How to Measure Anything: Finding the Value of "Intangibles" in Business, Hoboken, New Jersey, USA: John Wiley \& Sons.

Marinova, N. (2012), "Mechanisms in risk management in project activity for sustainable development, in: Jubilee International Congress Science, Education, Technologies "40 Years Bulgaria - Space Country". 12-14 September 2012, Shumen: Konstantin Preslavsky University of Shumen, University Press, Varna, Bulgaria, pp. 311-318.

Kirova M., Sheludko, I. and Velikova, P. (2012), "Ranking of risks in the operation of small energy plants", Contemporary Issues in Business, Management and Education '2012, Vilnus, Lithuania, pp. 26-40.

Hristova, M. (2007), "Expert evaluation of the quality of education in universities and methods for its objectivisation", Academic journal Mechanics. Transport. Communications, Vol. 1, pp. BG-0.1-BG-0.14.

Vasilev, H., Kyuchukov, R. and Byrdarski, N. (2013), "Method for evaluation of tenders at public procurements for street lighting, in: V Scientific conference, EF'2013, 2-5 September, Sozopol, Bulgaria, pp. 55-63.

NSI 2008, Classification of economic activities 2008, available at: http://www.nsi.bg/sites/default/files/files/publications/KID-2008.pdf, (accessed November 12, 2015). 